Arial 9. Volume 1(1), 1-10.

http://dx.doi.org/10.18608/jla.xxx

\title{
A Learning Analytics Approach to Monitoring the Quality of Online One-to-one Tutoring
}

\author{
Mutlu Cukurova ${ }^{1}$, Madiha Khan-Galaria1, Eva Millán², Rose Luckin ${ }^{1}$
}

\begin{abstract}
One-to-one online tutoring provided by human tutors can improve students' learning outcomes. However, monitoring the quality of such tutoring is a significant challenge. In this paper, we propose a learning analytics approach for monitoring online one-to-one tutoring quality. The approach analyses teacher behaviours and classifies tutoring sessions into those that are effective and those that are not effective. More specifically, we use sequential behaviour pattern mining to analyse tutoring sessions using the CM-SPAM algorithm and classify tutoring sessions into effective and less effective using the J-48 and JRIP decision tree classifiers. To show the feasibility of the approach, we analysed data from 2250 minutes of online one-to-one primary Maths tutoring sessions with 44 tutors from 8 schools. The results showed that the approach can classify tutors' effectiveness with high accuracy (F measures of 0.89 and 0.98 were achieved). The results also showed that effective tutors present significantly more frequent hint provision and proactive planning behaviours than their less effective colleagues in these online one-to-one sessions. Furthermore, effective tutors sequence their monitoring actions with appropriate pauses and initiations of students' self-correction behaviours. We conclude that the proposed approach is feasible to monitor the quality of online oneto-one primary Maths tutoring sessions.
\end{abstract}

Notes for Practice (research paper)

- The need to monitor the quality of online tutoring has increased significantly due to the impact of the COVID-19.

- An approach using sequential pattern mining and decision trees is proposed to monitor online one-toone primary Maths tutoring.

- Effective online tutors present statistically significantly more frequent appropriate hint provision and proactive planning behaviours in their sessions.

- Effective online tutors sequence monitoring actions with appropriate pausing and initiation of learner self-correction.

\section{Keywords}

Online One-to-one Tutoring, Learning Analytics, Sequential Pattern Mining, Decision Trees.

Submitted: 26/12/20 - Accepted: 11/10/21 - Published: DUE

Corresponding author ${ }^{1}$ Email: m.cukurova@ucl.ac.uk,m.khan.16@ucl.ac.uk, r.luckin@ucl.ac.uk Address: UCL Knowledge Lab, Institute of Education, University College London, 23- 29 Emerald Street, London, WC1N 3QS, United Kingdom. ORCID ID: 0000-0001-5843-4854

${ }^{2}$ Email: eva@Icc.uma.es Address: Universidad de Málaga · Avda. Cervantes, 2. 29071 MÁLAGA, Spain, ORCID ID 0000-0001-9178-7600

\section{Introduction}

Online tuition has the potential to provide an alternative to certain aspects of the traditional face to face model of education. However, there is good evidence to demonstrate that merely enabling online interaction opportunities for educators and learners is insufficient to achieve the expected learning outcomes. The quality of the tutoring that is provided is crucial to the effectiveness of online one-to-one tutoring (Donald et al., 2009; Torgerson et al., 2016; Rapanta et al., 2020; Hodges et al., 2020; Carter Jr et al., 2020). However, the process of evaluating the quality of online tutoring sessions is a significant challenge. Many schools assume that the frequency of tutoring interventions is the only success measure that is required. Issues concerning the quality of that tutoring are often ignored, not least because of a lack of practical and effective ways to monitor 
tutoring quality. Historically, there has been limited research into human-human online tuition, particularly with regards to monitoring the quality of the tutoring (e.g., Johnson \& Bratt, 2009; Kopp, Matteucci, \& Tomasetta, 2012).

One way to ensure the quality of online tutoring is to employ human evaluators, who can watch a regular, randomly selected set of online tutoring sessions, and score them using pre-agreed criteria to differentiate those tutors that are performing well, or adequately, from those who are not. However, there are various problems with this approach. Firstly, the online tutoring process is complex, meaning that the identification of the evaluation criteria in such contexts presents a significant challenge. Secondly, even after such evaluation criteria have been identified correctly, their implementation by the human evaluators creates further challenges. For example, the validity and reliability of the criteria, including how effectively each "tutor evaluator" can comprehend each criterion, and how much variance there is between different evaluators in their implementation of the same criteria. Third, if we can identify the success criteria of online tutoring sessions accurately, and if we assume that the human evaluators can implement the evaluation criteria objectively and effectively, such an evaluation process still relies heavily on human labour, which is expensive, in short supply, and hard to scale.

In this paper, we propose an approach to monitor the quality of online human-to-human tutoring sessions. The proposed solution first generates data from online tutoring behaviours with the help of a tagging interface. Then, these data are analysed with a sequential pattern algorithm (CM-SPAM) to identify emerging pattern frequencies. Finally, the emerging sequential patterns and their frequency values are used to build decision trees to classify effective and less effective tutoring sessions. There are two main research questions we investigate here:

1) What are the sequential behaviour patterns of effective and less effective online tutors?

2) To what extent can tutors' sequential pattern behaviours be used to accurately classify tutor effectiveness in online one-to-one tutoring settings?

In order to show the value of the approach, we implement it in an online primary Maths tutoring platform. The online oneto-one tutoring sessions we have sampled follow a structured format where the session starts with technical checks and warmup questions, followed by instructional content on lesson objectives, problem-solving on topic questions and concludes with a lesson plenary/reflection.

\section{Literature Review}

\subsection{Sequential Pattern Mining and Decision Trees}

The use of sequential pattern mining and decision tree modelling is not new in the area of learning analytics. However, these approaches are rarely employed together, or in combination with further classification methods. Neither have we found examples of their use to process human-observed behavioural data to explore tutor effectiveness in online one-to-one tutoring settings.

A survey of existing work illustrates, for example, the use of sequences of self- and socially shared regulatory activities from student $\log$ and online chat data to identify that more frequent and more diverse regulatory activities occur in data from successful groups when compared to less successful groups (Zheng et al., 2019). Similarly, sequential pattern mining, using the cSPADE algorithm applied to log data, has been used successfully when exploring whether differences exist between learners who viewed self-regulated learning (SRL) prompt videos and students who did not (Wong et al., 2019). A framework developed by Ozdagoglu et al. (2019) was used to analyse event log data from LMS platforms, using latent class analysis, and sequential pattern mining approaches. Using a similar approach, latent study patterns have been identified in data from learner interactions with course materials in a MOOC (Boroujeni \& Dillenbourg, 2019). In addition, there are examples of process mining being combined with sequence analysis to detect students' learning strategies (Matcha et al., 2020). For instance, pattern mining was used to detect the transition between learners' affective states in an open-ended learning environment and the frequency of these patterns was then correlated with learning outcomes (Andres et al. 2011). Sequence mining has been applied to predict whether students were ready for assessments by detecting patterns of behaviour that were associated with high and low performing students (Malekian et al., (2020), and to identify beneficial and harmful learning habits, as well as to guide instructor interventions when students transition between online platforms (Gitinabardet al., 2019). Similarly, a combination of analytics was used by Saint et al. (2020) to find patterns of self-regulated learning, including simple frequency measures, epistemic network analysis, temporal process mining and stochastic process mining.

A different approach, and one that is perhaps more closely aligned with the research reported here, can be found in the work of Kopp et al. (2012), who looked at the daily support practices of e-tutors and used cluster analysis to identify two 2 
profiles of e-tutors. Their study revealed that there is indeed a difference between experienced and inexperienced e-tutors in the way they support online collaboration. E-tutors with experience considered specific cognitive activities to be more important for effective online collaboration, and they seemed to be more familiar with detecting and intervening to avoid dysfunctional social phenomena. However, this study solely relied upon data from tutors' self-declared answers to a questionnaire, not their actual behaviour observations. Here, we present a learning analytics method for monitoring the effectiveness of online one-to-one tutoring sessions based on the analysis of tutor behaviours during online tutoring sessions.

The first step in the approach we propose here is to identify and describe potentially observable success behaviours that are exhibited by effective online tutors. We therefore initially present a review of the literature about effective tutoring behaviour. It is important to note that the purpose of this review is not to identify every possible indicator of successful tutoring behaviour, rather, it is to identify a few key features that can be operationalised and detected in online tutoring settings.

\subsection{Effective Tutoring Conceptualisations}

Numerous studies focused on effective tutor behaviours and their impact on the success of the tutoring process. Graesser et al. (2000) in their study aiming to understand the tutoring process, observe that tutoring sessions are largely driven by the tutor's agenda, which is mainly comprised of introducing topics, questions and problems. Lepper \& Woolverton (2002) explain that the tutoring process involves recurrent sequences of phases, including problem selection, problem presentation, problem solution, reflection and instruction. They utilise the INSPIRE model to identify tutor behaviours that demonstrate success, namely Intelligent, Nurturant, Socratic, Progressive, Indirect, Reflective, and Encouraging behaviours. Earlier research on oneto-one tutoring, on the other hand, emphasised the impact of tutors' subject knowledge (Schmidt et al., 1995) and argued that it is the most significant factor impacting upon tutor success and, directly or indirectly, tutors' subject knowledge shapes most of their tutoring behaviours. Similarly, Ritter et al. (2007) argued that in addition to declarative subject knowledge, tutors should have a strong procedural knowledge of the subject domain. In addition to the subject knowledge, Anania (1983)'s early study showed experimentally that the provision of cues and hints is a key aspect of the success of the tutoring process.

Other studies have focused on tutors' feedback as a variable affecting tutoring success (i.e Merrill et al., 1992; Shute, 2008). For instance, Black and Wiliam (1998) divide tutoring actions into two different functions: directive (tutor provides what needs to be fixed) and facilitative (tutor provides comments and suggestions). As the authors argue, based on the different expected learning outcomes, successful tutoring would require different functions. More recently, Shute (2008) proposed the concept of feedback specificity, which argues that successful tutoring requires specific feedback because uncertainty in feedback leads to a lack of motivation in pupils. The impact of systematic feedback on tutor success has also been shown by Narciss \& Huth (2004) in their tutoring feedback conceptual framework, as well as Kopp et al. (2012) in their study of differential practices by experienced and inexperienced tutors. Other studies have focused on the concrete aspects of tutors' feedback behaviour, such as the use of language (Schmidt et al., 1995) and the immediacy of tutors' behaviours in tutoring settings (Hastie et al., 2007). To emphasise the dialogic nature of the tutoring process, Graesser and colleagues put forward a pervasive student-tutor dialogue pattern of one-to-one online tutoring, consisting of a 5-step dialogue frame. Step 1: Tutor asks a question, Step 2: Student answers the question, Step 3: Tutor gives short feedback on the quality of student's answer, Step 4: Tutor and student collaboratively improve the quality of the answer, Step 5: Tutor assesses student's understanding of the answer (Graesser, 1993; Graesser et al., 1995).

At the metacognitive level, Lin et al. (2005) devised the term "adaptive metacognition" to represent a person's ability to adapt themselves flexibly to their environment in unexpected situations. Their approach does not advocate for tutors to be metacognitively engaged at all times, but rather to reflectively seek out "hidden features" in seemingly "routine situations" (p. 246). The approach has been shown to lead to success in tutoring practice. More recently, Wittwer et al. (2010) demonstrated that providing information about a pupil's current state of understanding to the tutors enabled online tutors to more effectively diagnose misconceptions and tailor instructional explanations to their students' needs. Interestingly, the opposite was true when tutors were provided with knowledge deficit information (Sleeman et al., 1989), suggesting that tutors are better at following a general sequence of instruction than they are at deconstructing a situation to address specific misconceptions (Wittwer et al., 2008).

There has also been a great amount of work that relates to the affective aspects of successful tutoring processes (Plass et al., 2014; Pardos et al., 2013; Wang et al., 2019). Most researchers argue for the impact of positive emotions that benefit students' motivation and learning outcomes (Amiri \& Ghonsooly, 2015), and negative emotions that have the opposite effect (c.f. Ryan \& Deci, 2009 for the impact of boredom). However, which emotions are negative and which are positive is not always crystal clear. For instance, although anxiety is traditionally considered as a negative emotion; Hwang et al. (2017) show that learners with higher levels of anxiety have better learning achievements than those with less anxiety. Simply put, emotions can "trigger, sustain, or reduce academic motivation and related volitional processes" (Pekrun et al., 2002, p.97). Therefore, 
successful tutoring also depends on a tutor's ability to manage their pupils' emotions.

Tutoring is a multidimensional, complex process and its successful delivery depends on a range of factors that could perhaps be broadly categorised as cognitive, metacognitive, and affective (Cukurova et al., 2017). However, the separation between these domains is not clear and various features can be considered under multiple categories. For example, feedback actions can be considered within any of the three categories depending on the feedback action's content and implementation. Also, although there is plenty of research on human tutoring in face-to-face environments and intelligent tutoring systems, online human tutoring is still a relatively understudied field. The quality of tutoring is key to the success of an online tutoring session, however, what exact tutor actions are more likely to lead to success is still a question with no clear answers. This is at least in part due to the numerous contextual factors playing a significant role in deciding whether a tutor behaviour is valuable for students' learning or not. For example, when Lepper \& Woolverton (2002) argue for the intelligent, nurturant, socratic, indirect, reflective, and encouraging characteristics of successful tutoring, they do not provide the exact details of how such characteristics can be implemented and monitored in real-world practice. Perhaps, the chaotic nature of the tutoring process can be used as an excuse for such ambiguous representations of successful tutoring. Just as in many educational practices, the subjective nature of tutor success makes its implementation, evaluation and training extremely challenging. It also makes its quality monitoring process very human-dependent in many real-world education settings.

\section{Methodology}

\subsection{Potential signifiers of tutor success in online tutoring}

In this subsection, we present the potential signifiers of effective tutor behaviours that we have identified from the literature reviewed above. These behaviour labels have been studied, either theoretically or experimentally, and argued to help monitor and detect the quality of tutoring in online settings. Table 1 presents the tutor behaviours we have identified and operationalised in building the behaviour tagging interface developed as part of our quality monitoring approach. Please note that the purpose of this section is to describe the potential effective tutoring signifiers tested in the particular tutoring context we researched (Primary Maths one-to-one tutoring). It is not to establish a set of criteria that would always universally lead to success in all tutoring sessions. Based on the literature reviewed, we have identified 7 behavioural indicators. Namely, appropriate pausing after questions, context-based questions/answers or examples, hint provision, monitoring and clarification actions/questions, proactive planning actions, initiation of self-correction, writing on the Virtual Classroom Environment (VCE) interface about the content discussed. Then we have used these behavioural indicators in a tagging interface built to tag tutor behaviours in real-time. Figure 1 shows the behaviour tagging interface used to tag tutors' behaviours.

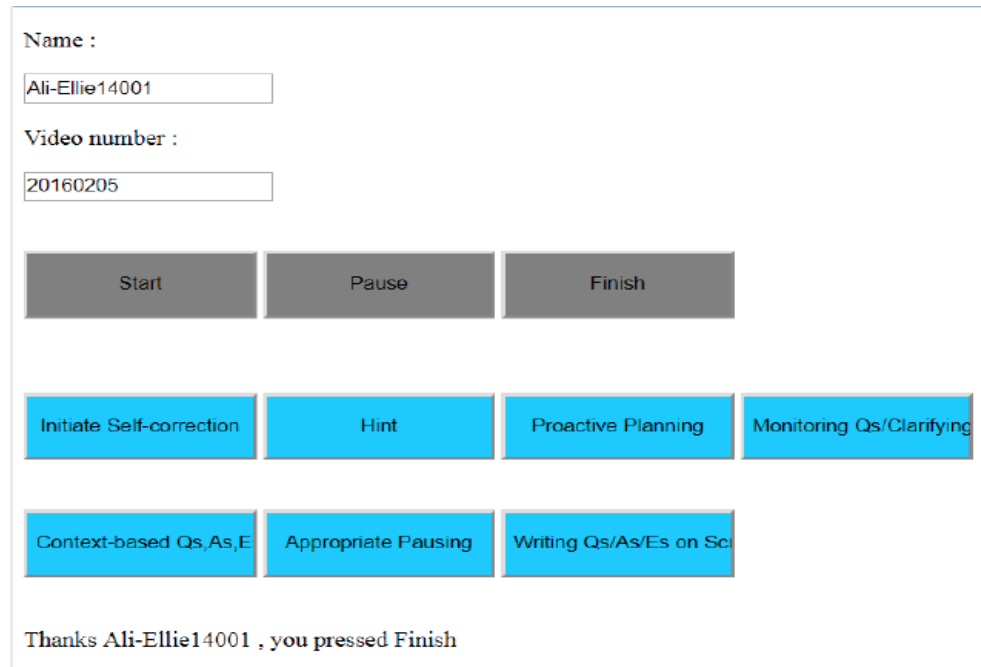

Figure 1. A screenshot of the annotation tool built for tagging tutor behaviour

These behaviours were observed as they emerge while tutors were teaching tutees using the virtual classroom interface presented in figure 2 . 


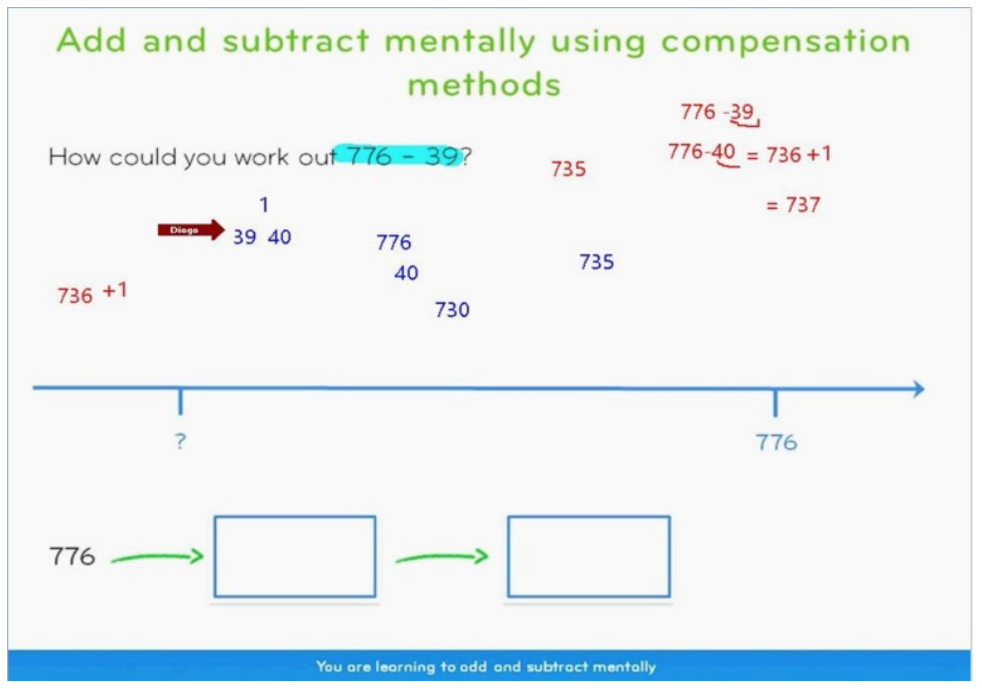

Figure 2: A screenshot of the online tutoring video interface

While choosing the potential signifiers for effective tutor behaviours, we have been particularly focused on experimental evidence. However, we also took theoretical considerations into account as the experimental evidence base for some theoretically effective tutor behaviours was weak and ambiguous. For instance, providing hints rather than direct instruction was often referred to as an effective tutoring behaviour in the literature. However, it was shown by D'Mello and Graesser (2012) that hints are more productive for high achieving students, whereas low achieving students should be provided with direct instruction in tutoring sessions. Similarly, it was also argued that successful tutors tend to be involved in delayed feedback actions more frequently (Butler et al., 2007). Indeed, Butler et al. (2007) have reported that students who received delayed feedback outperform their peers who received immediate feedback during instruction. On the other hand, in an earlier study, Kulik \& Kulik (1988) had found that immediate feedback could be more effective in terms of students' knowledge acquisition. However, there is also evidence that although a delay in feedback to a learner's response could enhance their performance in subsequent questions, students still prefer immediate feedback over delayed feedback (Lefevre, \& Cox, 2017). This has significant implications on the effectiveness of a tutoring session because a tutoring approach that contradicts students' preferences could negatively impact the student motivation and consequently, their engagement and learning. There might be various reasons for such differences, and, as argued by Mathan \& Koedinger (2002), the appropriate timing of feedback is not something that is fixed, but rather it is related to the nature of the task, the ability of the student and their individual needs and preferences. Regardless, feedback behaviours such as hint provision and appropriate pausing can indeed be used as potential indicators of effective tutoring. There is plenty of literature that argues for the benefit of waiting for students to reflect, modify, or elaborate on their answers as well as on tutor's questions (Walsh \& Sattes, 2016).

Moreover, successful tutoring sessions are argued to involve proactive planning behaviours by tutors (Wittwer et al., 2010). These behaviours are mainly context-specific. For instance, tutors in successful tutoring sessions begin each session by ensuring that both themselves and their tutees were oriented to the same section of the screen, checking the technical issues of the microphone and the tutor tools. They are also proactive in terms of engaging with the tutees, rather than asking them whether they understood the problem or example, they ask them to read the problem and ask them what they had understood from the problem or example. Such proactive planning is considered to be a strategy to gather more information about the tutees in online tutoring sessions, which in turn has been shown to have a significant impact on the effectiveness of tutoring sessions (Wittwer et al., 2010).

Following the effective feedback theme, the type of questions a tutor poses appears to have an impact on the quality of a tutoring session. In previous work, it was also observed that tutees usually benefit from seeing the questions, answers or examples clearly written on the screen provided during online tuition. In their seminal work, Shorrocks-Taylor \& Hargreaves (1999) showed that the use of apparatus to present the questions and answers clearly to tutees facilitated them to better understand what they were expected to do and what was required of them to work out answers to the questions. Similarly, the contextualisation of the information presented is an action that frequently occurs in successful tutoring sessions. Particularly, within the tutoring of Maths. Shield \& Dole (2013) argued that mathematical questions based on authentic and real-life contexts lead to students' deep reasoning, therefore leading to more productive tutoring sessions. Similarly, Bell (1993) showed that the presentation of content within a familiar context can allow students to extend this information to other related contexts, therefore leading to better transfer of mathematical knowledge.

5

ISSN 1929-7750 (online). The Journal of Learning Analytics works under a Creative Commons License, Attribution - NonCommercial-NoDerivs 3.0 Unported (CC BY-NC-ND 3.0) 
Table 1: Tutor behaviours identified from the literature and coded with the tagging interface.

\begin{tabular}{|c|c|c|c|}
\hline Codes & Tutor behaviours & Definition of behaviour & Reference \\
\hline $\mathrm{a}$ & $\begin{array}{l}\text { Appropriate pausing after } \\
\text { questions }\end{array}$ & $\begin{array}{l}\text { Tutor pauses after asking a question, to allow the } \\
\text { learner time to respond }\end{array}$ & Walsh \& Sattes (2016) \\
\hline $\mathrm{c}$ & $\begin{array}{l}\text { Context-based questions, } \\
\text { answers, or examples }\end{array}$ & $\begin{array}{l}\text { Tutor asks the learner questions or provides } \\
\text { answers and examples that are contextually } \\
\text { relevant, to guide the learners' understanding }\end{array}$ & Shield \& Dole (2013) \\
\hline \multirow[t]{2}{*}{$\mathrm{h}$} & \multirow[t]{2}{*}{ Hint provision } & \multirow{2}{*}{$\begin{array}{l}\text { Tutor provides a small piece of information to } \\
\text { scaffold the learner as they work through a problem }\end{array}$} & D’Mello \& Graesser (2012) \\
\hline & & & Mathan \& Koedinger (2002) \\
\hline $\mathrm{m}$ & $\begin{array}{l}\text { Monitoring and clarification } \\
\text { actions or questions }\end{array}$ & $\begin{array}{l}\text { Tutor passively observes a learner or takes clarifying } \\
\text { actions }\end{array}$ & Lepper \& Woolverton (2002) \\
\hline $\mathrm{p}$ & Proactive planning action & $\begin{array}{l}\text { Tutor supports the learner in planning an approach } \\
\text { to a question and engages with them proactively }\end{array}$ & Wittwer et al. (2010) \\
\hline $\mathrm{s}$ & Initiation of self-correction & $\begin{array}{l}\text { Tutor prompts the learner to detect and correct } \\
\text { their mistakes }\end{array}$ & Wylie \& Chi (2014) \\
\hline $\mathrm{w}$ & $\begin{array}{l}\text { Writing on the } \\
\text { virtual classroom interface }\end{array}$ & $\begin{array}{l}\text { Tutor writes on the virtual classroom interface to } \\
\text { help explain content to the learner }\end{array}$ & $\begin{array}{l}\text { Shorrocks-Taylor \& } \\
\text { Hargreaves (1999) }\end{array}$ \\
\hline
\end{tabular}

\subsection{Context of the Online Tutoring Platform}

For our empirical work, we partnered with an industrial supplier named Third Space Learning (TSL), which delivers Maths tutoring for primary school children aged 9-10 years using an online tutoring platform. Tutoring sessions are organised by subject topic, and learners are diagnosed with a specific curriculum when they are enrolled in TSL. A tutor is allocated to a learner based on availability, and this tutor will typically deliver most, if not all, of the sessions in the learner's programme. Each session lasts about 45 minutes and follows the same format: a warm-up question, lesson objectives, topic questions and then the lesson plenary/reflection. Tutors guide the learners through the session, and there is a level of flexibility over the structure of the session; for example, tutors can choose to skip certain questions or introduce new ones. In total, online Math tutoring sessions were sampled from 8 schools.

The online tutoring platform consists of an interactive whiteboard and tools, where the lessonobjectives, topic questions and plenary questions are set out. The learner and the tutor communicate through audio and they use the pointer and whiteboard tools to draw, type and erase (please see figure 2). If the audio is interrupted, the learner and tutor can also chat through the messaging box displayed on the side of the screen, but there is no video available of either the learner or tutor. Tutors can reward learners for their work by giving them effort points, or presenting them with an emoji or picture.

In the online tutoring environment, learners and tutors log into the system, in which the learner works through a predesigned online set of questions, with the guidance of their human tutor. All data from tutors and tutees were anonymised and their consent was obtained before the data collection took place.

\subsection{Tutor Evaluation}

For ground truth about the effectiveness of online tutoring sessions, we have used a combination of metrics. Tutors are evaluated using four metrics. Firstly, learners rate sessions on several criteria, including enjoyment and clarity. Secondly, learner outcomes for a tutor (i.e. the difference between the pre-diagnostic test score and the post-diagnostic test score) are computed. Thirdly, a panel of three human evaluators (experienced online primary Maths tutors) evaluate and score a randomly selected sample of sessions for a tutor. A minimum of 2 sessions are evaluated for each tutor, and the scores from the human evaluators are averaged to provide an overall score. Tutors are evaluated against 28 criteria, including tutor interactions (impacting learning and mindset), subject knowledge, language, familiarity and safeguarding. The criteria used for human evaluations can be seen here ${ }^{1}$. Finally, the tutors' scores on the subject matter (Maths) and English tests were used in the evaluation. These four metrics were weighted equally and used to provide an overall evaluation score for each tutor. Based on

\footnotetext{
${ }^{1} \underline{\text { https://bit.ly/3uzhsxF }}$

6
} 
this aggregated score for tutors, those tutors whose score was higher than the average score for all tutors were categorised as effective, and those with a less than average score were categorised as less effective tutors.

\subsection{Participants and tutor behaviour labelling procedure}

In total, 2250 mins of online tutoring were recorded from 44 tutors. 26 males and 18 female tutors were involved in the research and delivered the tutoring through the online platform to students from 8 different schools. For each tutor, their practice was evaluated as one incident based on one of their tutoring sessions which lasted on average 50 mins. Schools and tutors were from varied backgrounds to improve the representativeness of the sample. The student and tutor were matched randomly depending on the availability of tutors and the demands of the tutees. Using the combined metrics described in section 3.2, 24 tutors were categorised as effective tutors and 20 tutors were categorised as less effective tutors. Tutor behaviours were tagged by human observers using the bespoke tagging tool built (figure 1). Human evaluators were experienced primary Maths tutors who had experience in delivering online tutoring. They were provided with a three-hour workshop during which the tagging tool was introduced and the behaviours were defined and exemplified. Afterwards, they were asked to watch online tutoring sessions and do the tagging in real-time. If they had any confusion or questions they were asked to pause or reverse the recording of a session.

It is important to note that, we initially considered more behaviour indicators from the literature reviewed above, but seven indicators were the suitable number for human coders to reliably undertake the tagging task while observing online tutor behaviours in real-time. In our pilot studies, we have attempted to tag up to ten tutor behaviours. The inter-coder reliability value when human evaluators used 7 indicator behaviours to code was significantly higher, compared to when they used 10 indicators to code (ordinal $\mathrm{k}$ alpha $=0.623 \mathrm{vs} 0.892$ ). We chose the seven indicators that were best understood and easy to be implemented by the human evaluators. All tags as well as their timestamps were collected on a local SQL database. Logs involved the video ID, human observer ID, tag name, and timestamp. Then, the log files from the SQL database were exported for data analysis and modelling.

\subsection{Pre-processing for the sequential pattern mining and the classification tasks}

To be able to observe at which section of a 45-min long tutoring session sequential behaviour patterns show differences, we structured each session into time bins based on the structured learning design of the online tutoring sessions described in section 3. A typical session was structured as shown in figure 5.

\begin{tabular}{l|l|l|l|l}
\hline $\begin{array}{l}\text { Technical } \\
\text { checks } \\
(\sim 2 \text { minutes })\end{array}$ & $\begin{array}{l}\text { Warm up } \\
(\sim 5-10 \\
\text { minutes })\end{array}$ & $\begin{array}{l}\text { Lesson } \\
\text { objectives } \\
(\sim 10 \text { minutes })\end{array}$ & $\begin{array}{l}\text { Topic questions } \\
(\sim 20-25 \\
\text { minutes })\end{array}$ & $\begin{array}{l}\text { Lesson } \\
\text { plenary/ } \\
\text { reflection } \\
\sim 5-10 \\
\text { minutes })\end{array}$ \\
\hline
\end{tabular}

Figure 5: Structure of an online tutoring session into time-bins

We then used the SPMF library to find the sequences of behaviours that appeared more frequently in effective and less effective tutors' online tutoring sessions. SPMF is an open-source data mining library written in Java, specialized in pattern mining (https://www.philippe-fournier-viger.com/spmf/index.php). More specifically, we used the CM-SPAM algorithm, a fast vertical mining of sequential patterns approach that uses co-occurrence information (Fournier-Viger et al., 2014). CMSPAM discovers all frequent sequential patterns occurring in a sequence database. We have used the parameters below in the data analysis. Minimum pattern length was set as 2 items and maximum pattern length was set to the maximum possible number of items. We did not specify any particular required item in the mining process and set the maximum gap between items to 1 . Finally, we used minsup value as $\% 50$ which meant that a sequential pattern is considered as frequent when it appears more than half of the total number of sequences.

To build a classification model that would help us automatically categorise tutors into effective and less effective tutor classes based on their behaviour patterns, we first calculated the number of times each sequential pattern emerged in each session and normalized these values according to the total number of patterns in the session. Total pattern lengths varied from 83 to 212 in 44 sessions. Then, using WEKA software, we built several classifiers and tested the performance of each of these models using 10 -fold cross-validation. 


\section{Results}

\subsection{Frequency of Tutor Behaviours}

First, we studied how many of the 44 tutors had each particular tutor behaviour tagged with the tool in their sessions. The frequency of tutors who present each behaviour at least once in the sessions is presented in table 2. Appropriate pausing, Context-based questioning, Monitoring and clarification actions, Initiation of self-correction and Writing on the VCE interface about the content discussed were all exhibited at least once by almost all tutors in their sessions. However, there were differences in the appropriate hint provision and proactive planning behaviours between less effective tutors' sessions compared to effective tutors' sessions. Although these behaviours were presented at least once by almost all effective tutors, 8 of the less effective tutors never presented an appropriate hint provision behaviour in their sessions. Also, 12 less effective tutors never presented proactive planning behaviours in their sessions. The results indicate that less effective tutors do not present appropriate hint provision and proactive planning behaviours as frequently as effective tutors.

Table 2: Number of tutors each behaviour was observed.

\begin{tabular}{|c|c|c|c|c|c|c|c|c|}
\hline GROUP & ACTION & \begin{tabular}{|c|} 
NUMBER OF \\
TUTORS THE \\
BEHAVIOUR \\
OBSERVED \\
\end{tabular} & GROUP & ACTION & $\begin{array}{l}\text { NUMBER OF } \\
\text { TUTORS THE } \\
\text { BEHAVIOUR } \\
\text { OBSERVED }\end{array}$ & GROUP & ACTION & \begin{tabular}{|} 
NUMBER OF \\
TUTORS THE \\
BEHAVIOUR \\
OBSERVED \\
\end{tabular} \\
\hline $\begin{array}{l}\text { ALL } \\
\text { Tutors }\end{array}$ & $\mathrm{m}$ & 44 & $\begin{array}{c}\text { Effective } \\
\text { Tutors }\end{array}$ & $\mathrm{m}$ & 24 & \begin{tabular}{|c|} 
Less \\
Effective \\
Tutors
\end{tabular} & $\mathrm{c}$ & 20 \\
\hline $\begin{array}{l}\text { ALL } \\
\text { Tutors }\end{array}$ & $\mathrm{c}$ & 44 & $\begin{array}{c}\text { Effective } \\
\text { Tutors }\end{array}$ & $\mathrm{a}$ & 24 & \begin{tabular}{|c|} 
Less \\
Effective \\
Tutors \\
\end{tabular} & $\mathrm{m}$ & 20 \\
\hline $\begin{array}{l}\text { ALL } \\
\text { Tutors }\end{array}$ & $\mathrm{a}$ & 43 & $\begin{array}{c}\text { Effective } \\
\text { Tutors }\end{array}$ & $\mathrm{c}$ & 24 & \begin{tabular}{|c|} 
Less \\
Effective \\
Tutors \\
\end{tabular} & a & 19 \\
\hline $\begin{array}{l}\text { ALL } \\
\text { Tutors }\end{array}$ & $\mathrm{s}$ & 43 & $\begin{array}{c}\text { Effective } \\
\text { Tutors }\end{array}$ & $\mathrm{h}$ & 24 & \begin{tabular}{|c|} 
Less \\
Effective \\
Tutors \\
\end{tabular} & $\mathrm{s}$ & 19 \\
\hline $\begin{array}{l}\text { ALL } \\
\text { Tutors }\end{array}$ & $\mathrm{w}$ & 41 & $\begin{array}{c}\text { Effective } \\
\text { Tutors }\end{array}$ & $\mathrm{s}$ & 24 & \begin{tabular}{|c|} 
Less \\
Effective \\
Tutors
\end{tabular} & $\mathrm{w}$ & 18 \\
\hline $\begin{array}{l}\text { ALL } \\
\text { Tutors }\end{array}$ & h & 36 & $\begin{array}{c}\text { Effective } \\
\text { Tutors }\end{array}$ & $\mathrm{w}$ & 23 & \begin{tabular}{|c|} 
Less \\
Effective \\
Tutors \\
\end{tabular} & $\mathrm{h}$ & 12 \\
\hline $\begin{array}{l}\text { ALL } \\
\text { Tutors }\end{array}$ & $\mathrm{p}$ & 30 & $\begin{array}{c}\text { Effective } \\
\text { Tutors }\end{array}$ & $\mathrm{p}$ & 22 & \begin{tabular}{|c|} 
Less \\
Effective \\
Tutors \\
\end{tabular} & $\mathrm{p}$ & 8 \\
\hline \multicolumn{9}{|c|}{$\begin{array}{l}\text { a (Appropriate pausing after questions), c (Context-based questions, answers, or } \\
\text { examples), h (Hint provision), m (Monitoring and clarification actions or questions), } \\
\text { p (Proactive planning action), s (Initiation of self-correction), w (Writing on the virtual } \\
\text { interface) }\end{array}$} \\
\hline
\end{tabular}

\subsection{Frequency of tutor behaviour patterns in different stages of an online tutoring session}

The sequential pattern analysis below shows that behaviour pattern differences become particularly apparent during the initial warm-up questions, the instructional section covering the lesson objectives and the problem-solving on-topic questions stages of a typical tutoring session on the TSL platform. On the other hand, during the technical checks in the beginning and the lesson plenary/reflection phases at the end of the online tutoring sessions, distinctions between effective and less effective tutors' behaviours were not statistically significant. 
Table 3: Sequential behaviour patterns in different stages of online tutoring (* indicates statistical significance $p<.05)$.

\begin{tabular}{|c|c|c|c|c|}
\hline Stage & Pattern & $\begin{array}{c}\text { Effective } \\
\text { Tutors }\end{array}$ & $\begin{array}{c}\text { Less Effective } \\
\text { Tutors }\end{array}$ & P( $\left.\boldsymbol{X}^{2}\right)$ \\
\hline Technical checks & $\mathrm{p}, \mathrm{c}$ & 17 & 16 & 21.05 \\
\hline Warm-up & $\mathrm{m}, \mathrm{a}$ & 24 & 0 & $0.01 *$ \\
\hline Warm-up & $\mathrm{a}, \mathrm{m}$ & 24 & 0 & $0.01 *$ \\
\hline Warm-up & $\mathrm{m}, \mathrm{m}$ & 0 & 18 & $0.00 *$ \\
\hline Warm-up & $\mathrm{m}, \mathrm{m}, \mathrm{m}$ & 0 & 10 & $0.01 *$ \\
\hline Instruction & $\mathrm{m}, \mathrm{a}$ & 24 & 12 & 57.15 \\
\hline Instruction & $\mathrm{a}, \mathrm{m}$ & 24 & 11 & 42.94 \\
\hline Instruction & $\mathrm{m}, \mathrm{a}, \mathrm{m}$ & 22 & 0 & $0.02 *$ \\
\hline Instruction & $\mathrm{m}, \mathrm{s}$ & 20 & 0 & 0.05 \\
\hline Instruction & $\mathrm{m}, \mathrm{m}$ & 0 & 20 & $0.00 *$ \\
\hline Instruction & $\mathrm{m}, \mathrm{m}, \mathrm{m}$ & 0 & 15 & $0.00 *$ \\
\hline Problem-solving & $\mathrm{m}, \mathrm{a}$ & 24 & 0 & $0.01 *$ \\
\hline Problem-solving & $\mathrm{a}, \mathrm{m}$ & 24 & 0 & $0.01 *$ \\
\hline Problem-solving & $\mathrm{m}, \mathrm{m}$ & 23 & 0 & $0.02 *$ \\
\hline Problem-solving & $\mathrm{m}, \mathrm{a}, \mathrm{m}$ & 23 & 0 & $0.02^{*}$ \\
\hline Problem-solving & $\mathrm{a}, \mathrm{m}, \mathrm{a}$ & 23 & 0 & $0.02 *$ \\
\hline Problem-solving & $\mathrm{m}, \mathrm{m}, \mathrm{m}$ & 0 & 19 & $0.00 *$ \\
\hline Problem-solving & $\mathrm{m}, \mathrm{m}, \mathrm{m}, \mathrm{m}$ & 0 & 14 & $0.00^{*}$ \\
\hline Problem-solving & $\mathrm{m}, \mathrm{m}, \mathrm{m}, \mathrm{m}, \mathrm{m}$ & 0 & 13 & $0.00 *$ \\
\hline Problem-solving & $\mathrm{m}, \mathrm{m}, \mathrm{m}, \mathrm{m}, \mathrm{m}, \mathrm{m}$ & 0 & 13 & $0.01 *$ \\
\hline Reflection & $\mathrm{m}, \mathrm{s}$ & & 5.53 \\
\hline
\end{tabular}

Table 3 illustrates the chi-squared tests undertaken to compare the statistical significance of the differences between the frequency of sequential patterns of behaviours. The results show that there are statistically significant differences between certain sequential behaviour patterns occurring in the warm-up questions, lesson objectives and topic questions stages ( $<<.05$ ). The purpose of this exploratory investigation was to decide which behaviour patterns are likely to have a significant difference that can be used in decision tree classifications. Therefore, to avoid a possible type II error, no statistical correction was made to the $\mathrm{p}$ values.

Looking at table 3, a couple of interesting results emerge in the differences between the effective and less effective tutors' behaviours in online tutoring sessions. First of all, it is interesting to observe that effective tutors sequence their monitoring behaviours with appropriate pausing behaviours. That means monitoring questions or actions are frequently either followed by or preceded by, enough time and space for students to think and reflect on their actions. On the other hand, less effective tutors sequence their monitoring actions without allowing appropriate space and time for students' reflections. As can also be seen, less effective tutors might present up to six monitoring actions in a sequence. However, such long monitoring action sequences is non-existent in effective tutors' sessions. Furthermore, particularly during the instructional section covering the lesson objectives, effective tutors sequence their monitoring actions with initiating students' self-correction behaviours. On the contrary, none of the less effective tutors presented this sequence of monitoring actions and initiations of students' selfcorrection. It is also interesting to observe that there was no statistically significant difference between effective and lesseffective tutors in the sequential patterns observed during technical checks and the reflection phase of the tutoring sessions.

\subsection{Classification models for effective and less effective tutors}

The best result was achieved by separating the normalised sequential tutor behaviour patterns into 3 bins (namely; low frequency, medium frequency and high frequency) and with the use of the JRIP classifier. The decision tree's classification rule identified is given below. 


$$
\begin{gathered}
\text { if 'as' pattern }=\text { 'low frequency' }=>\text { Label }=\text { Less effective tutor } \\
\text { else }=>\text { Label }=\text { Effective tutor }
\end{gathered}
$$

With this rule as tested with a 10-fold-cross-validation; 39 out of 44 instances were correctly classified and an F-measure of 0.887 was achieved. Tables 4 and 5 below show the detailed accuracy values and the confusion matrix of the classification model.

This result emphasizes the distinctive value of "as" behaviour sequence in online one-to-one primary Maths tutoring sessions which follows appropriate pausing behaviours with the initiation of students' self-corrections.

Tables 4 and 5: Detailed accuracy values by class and Confusion matrix for the 3 bins model

\begin{tabular}{|c|c|c|c|}
\hline Precision & Recall & F-Measure & Class \\
\hline 0.952 & 0.833 & 0.889 & Effective Tutor \\
\hline 0.826 & 0.950 & 0.884 & Less Effective Tutor \\
\hline
\end{tabular}

\begin{tabular}{|c|c|c|}
\hline Effective Tutor & Less Effective Tutor & Classified as \\
\hline 20 & 4 & Effective Tutor \\
\hline 1 & 19 & Less Effective Tutor \\
\hline
\end{tabular}

To build a more detailed classification model and to potentially improve the classification performance; we also tried a model that used the normalised frequency of behaviours according to session duration rather than pattern length. In this case, the best results were achieved by discretizing the variables in 4 bins (very low, low, high, very high frequency). We used the $\mathrm{J} 48$ algorithm for the classification task. The performance was not further improved, but high accuracy of $88.64 \%$ was reached. As the decision tree shows (figure 6), the root of the tree was the pattern of following appropriate pausing behaviours with self-initiation of students' explanations, however, there was further consideration of the 'ama' tutor behaviour pattern. This pattern refers to appropriate pausing behaviours being sequenced with monitoring actions and questions.

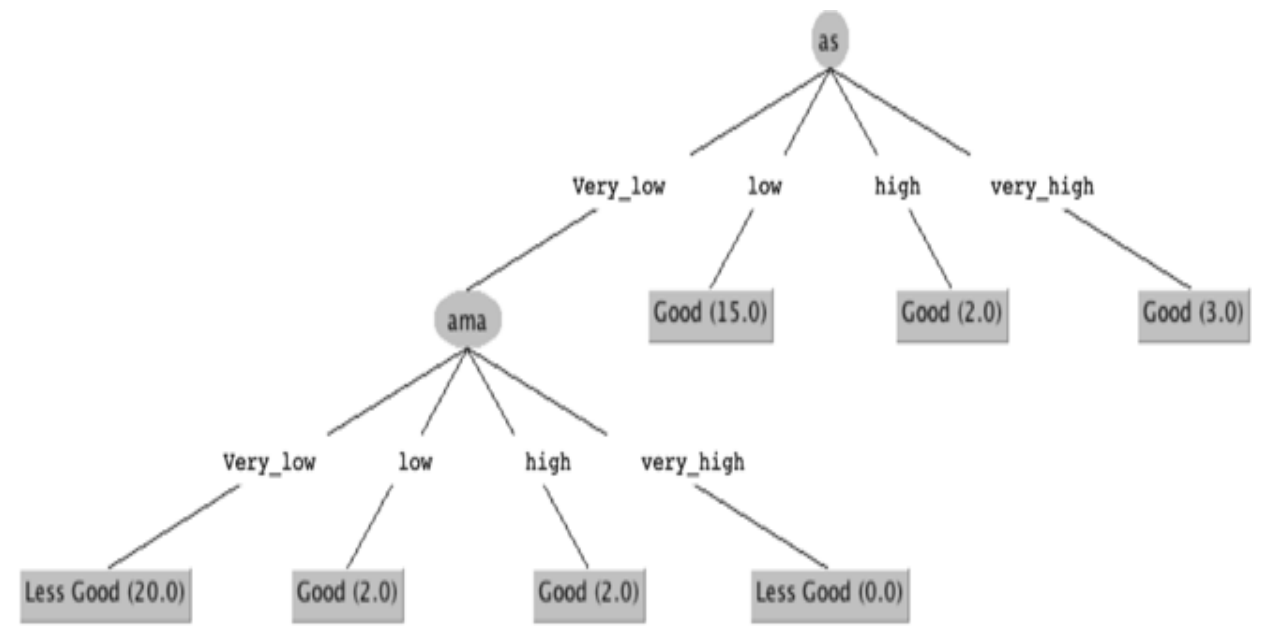

Figure 6: Decision tree for the classification of online tutors based on sequential behaviour patterns normalised for session time

Finally, we investigated the performance of a model that uses longer sequential behaviour patterns, having at least four behaviours. For this task, we defined variables to measure if a pattern was present or absent during a tutoring session (yes/no values) and then again used the J48 algorithm to complete the classification task. The model achieved 97,73\% accuracy with the F-measure of 0.977 . This was the highest accuracy performance we observed in our data. As the decision tree in figure 7 shows, similarly to previous decision trees, the distinctive patterns were still related to the monitoring and appropriate pausing behaviours of tutors. Tables 6 and 7 below present the detailed accuracy values and the confusion matrix for this decision tree. 


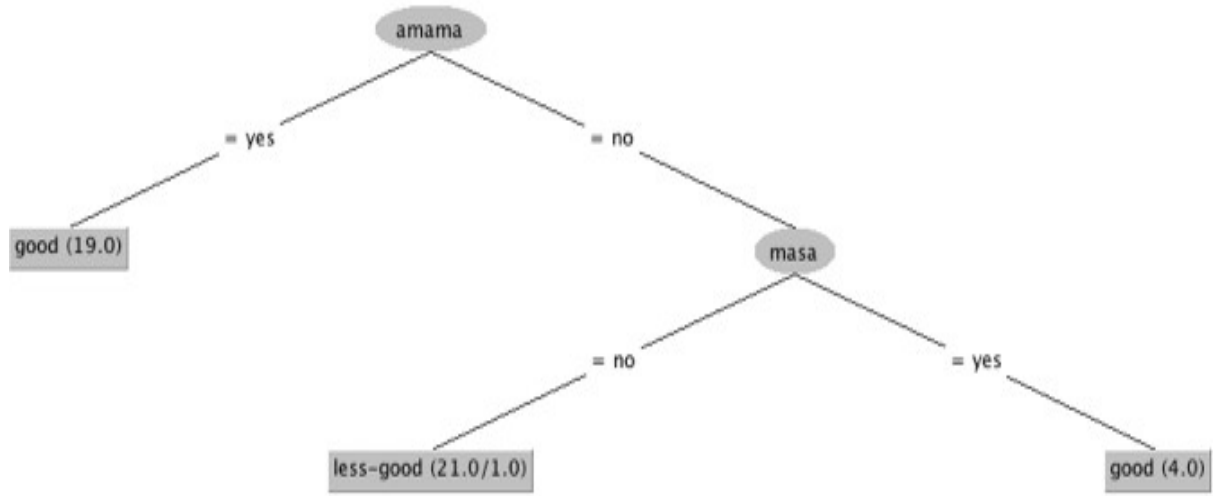

Figure 7: Decision tree for the classification of online tutors based on sequential behaviour patterns of a minimum of four behaviours

Tables 6 and 7: Detailed accuracy values by class and Confusion matrix for the long sequence model

\begin{tabular}{|c|c|c|c|}
\hline Precision & Recall & F-Measure & Class \\
\hline 1.000 & 0.958 & 0.979 & Effective Tutor \\
\hline 0.952 & 1.000 & 0.976 & Less Effective Tutor \\
\hline
\end{tabular}

\begin{tabular}{|c|c|c|}
\hline Effective Tutor & Less Effective Tutor & Classified as \\
\hline 23 & 1 & Effective Tutor \\
\hline 0 & 20 & Less Effective Tutor \\
\hline
\end{tabular}

\section{Discussion}

In this paper, we present a learning analytics approach to monitoring the quality of online one-to-one primary Maths tutoring. The proposed solution first uses potential success indicators of tutor behaviours to generate observation data from online tutoring sessions with the help of a bespoke tagging interface. Human evaluators tag seven indicators of effective tutoring behaviours as they occur while they are watching the recordings of online one-to-one tutoring sessions in real-time. Then, the data generated is analysed with the CM-SPAM sequential pattern algorithm to calculate the frequency of sequential tutor behaviours from online tutoring sessions. The frequencies of behaviour sequences are then used to build JRIP and J-48 decision tree classifiers to categorise effective and less effective tutors successfully. The results presented in this paper provide a promising proof of concept of our approach that can detect and classify effective and less effective tutor behaviours in online tutoring sessions with high accuracy.

More specifically, we have investigated two research questions. First, we looked at the behaviour patterns of effective and less effective online tutors. Our results showed that less effective tutors are less likely to present appropriate hint provision in their sessions. As discussed in our literature review, there is plenty of previous research showing the value of appropriate hint provision in face-to-face teaching settings (i.e Anania, 1983; Merrill et al., 1992; Shute, 2008). Our results confirm these findings and extend them showing the distinctive value of appropriate hint provision in effective one-to-one online tutoring. D'Mello \& Graesser (2012) showed that hints are more productive for high achieving students whereas, low achieving students should be provided with direct instruction in tutoring sessions. However, in our evaluation, the overall effective tutor behaviours were associated with hint provision rather than direct instruction. It is worth noting that, in this study, we did not categorise students into high or low achiever categories which might have influenced the observed results.

The results also show that effective tutors exhibit proactive planning behaviours significantly more frequently than less effective tutors. These behaviours include, but are not limited to, effective online tutors beginning each slide of the presentation by ensuring that both themselves and their tutees were oriented to the same section of the screen, checking the technical issues of the microphone and the tutor tools, engaging with the students proactively through asking them to read the problem and asking them what they have understood from the problem, in order to address any possible misunderstandings at an early stage. These results are in alignment with previous research showing the significant impact of proactive planning behaviours on the effectiveness of tutoring sessions (Wittwer et al., 2010).

To provide more detailed insights into effective practice we looked at the sequences of online tutor behaviours and compared effective tutor behaviours with less effective ones. Indeed, statistically significant differences were observed in the sequences of behaviours presented by effective and less effective online tutors. For instance, effective tutors frequently 
sequence their monitoring behaviours with appropriate pausing behaviours, whereas less effective tutors sequence their monitoring behaviours with further monitoring actions and questions, rather than pausing and allowing enough time for students to think and reflect. These results are aligned with previous work showing that successful tutors frequently present delayed feedback and monitoring actions, to allow space for learners to process information and reflect (Butler et al., 2007; Kulik \& Kulik, 1988). Although such appropriate pausing behaviours appear to be indicative of effective tutor behaviours in online one-to-one tutoring settings, the learner implications of such behaviours are not considered in this research article. As argued by Lefevre \& Cox (2017) students usually prefer immediate support and monitoring over delayed actions, which might have significant implications on the effectiveness of an online tutoring session due to learners' unpleasant experiences and their lack of motivation to engage. Also, although, we have identified that effective tutors present appropriate pausing behaviours sequenced with their monitoring behaviours, the timing of such behaviours is not fixed and is dependent upon the nature of the task, the ability of the learner and their individual needs and preferences (Mathan \& Koedinger, 2002).

The results also show that less effective tutors can present up to six monitoring actions in a sequence, however long monitoring action sequences are non-existent in effective tutors' sessions. In addition to sequencing their monitoring actions with appropriate pausing, effective tutors also sequence their monitoring actions with initiating students' self-correction behaviour. Less effective tutors do not present this sequence of monitoring actions combined with the initiation of students' self-correction. Self-correction requires learners to realise the process of their understanding, and recognise the gaps in their knowledge through thinking and reflections and it can lead to higher learning outcomes in various fields including computer programming, biology, probability and reading comprehension (Wylie \& Chi, 2014). As argued by Chi et al. (1989) selfcorrection opportunities also promote the process of knowledge transfer. Besides, prompted self-correction made by online tutors might also induce learners' metacognitive development to a certain extent (Chi et al., 1994; Hacker et al., 2015). However, in this research paper, we have not focused on the impact of tutor behaviours on students' metacognitive skills. This particular literature gap provides multiple opportunities for future research. See for instance early work focusing on tutor behaviours that stimulate learner metacognition in online tutoring sessions (Khan-Galaria, Cukurova, \& Luckin, 2020).

In our results, we found no statistically significant difference in the sequential patterns of effective and less effective tutors during the initial technical check stage as well as the reflection/plenary phases of online tutoring sessions. On the other hand, behaviour pattern differences emerged during the warm-up questions, and the instructional stage where the content of the lesson objectives are covered and the problem-solving stages of the online tutoring session. These results might be specific to the particular online tutoring context we have investigated. Although our results suggest that evaluations of online tutoring sessions might benefit from focusing on those sections in which significant behaviour pattern differences emerge, we recognise that not all online tutoring sessions would follow such a structured approach, neither they would have the same stages of the sessions we have investigated. Therefore, these findings should be investigated further in terms of their potential to be transferred to different online tutoring contexts.

Lastly, in our second research question, we intended to investigate to what extent tutors' sequential pattern behaviours can be used to accurately classify tutor effectiveness in online tutoring settings. The results show that we have achieved \%88.64 and $\% 97.73$ accuracy values with different classification trees. Due to the significantly small sample size as well as the small number of sequence frequencies investigated here, the overfitting in our models is a significant concern. However, the high accuracy values achieved are promising for future research to investigate the potential of the approach presented here at larger scales. The roots and the leaves of the classification trees were mainly associated with the sequences of tutor behaviours that combine monitoring actions with appropriate pausing and the initiation of self-correction behaviours. Because these sequences were statistically significantly different behaviour patterns between effective and less effective tutors in online tutoring settings, these results are not surprising. The highest accuracy in decision trees was achieved when we used longer sequential behaviour patterns as input. For instance, when we only took into account four or more behaviour sequence patterns, the decision tree was able to classify all less effective tutors correctly and it only mislabeled one effective tutor as less effective by error. These results are similar to previous research in the use of sequential pattern mining approaches in education showing that longer behaviour patterns might be stronger indicators of differences. See, for instance, Kinnebrew et al. (2013) for the sequences of online learners behaviours in a digital learning environment, or Martinez-Maldonado et al. (2010) for students' sequential patterns of collaborative learning activity around an interactive tabletop.

\subsection{Limitations}

In this section, we discuss some limitations of the work presented in this paper.

As stated in section 2.2, the original purpose of the work presented here is to identify potential signifiers in the particular tutoring context we are studying (primary Maths one-to-one tutoring). The methodology proposed here has the potential to be

12

ISSN 1929-7750 (online). The Journal of Learning Analytics works under a Creative Commons License, Attribution - NonCommercial-NoDerivs 3.0 Unported (CC BY-NC-ND 3.0) 
used in similar subjects' online tutoring, for example to more advanced mathematics or other problem-solving based domains in which learning has a similar methodology (e.g., physics). This requires further research. However, the application of this approach to other domains, such as arts and humanities, may not be very productive. Here, we are only focusing on tutor behaviours and we do not consider the wider context for these behaviours, such as learner actions. Effective tutor behaviours are highly contextualised and hard to interpret in isolation. Although the indicator behaviours we have chosen are purposefully easy to be interpreted, further research that examined tutor-learner interactions in context would enable a more rounded view of tutor practices that can be associated with different clusters of tutors. In our current work, we are also investigating the potential of process mining approaches that have the potential to observe tutor behaviours in a more contextually meaningful manner. Also, there are still challenges with the scalability of the approach proposed here. The approach proposed brings in significant efficiency compared to the traditional quality evaluation of an online tutoring session (evaluation of a session using the metrics in section 3.2 takes around 3 hours, whereas the learning analytics approach presented here can be implemented in real-time in a 45 mins session). More importantly, decision trees built using this approach can reach a classification decision based on a small number of tagged tutor behaviours. As more reliable models are built with more representative data in the future, classification decisions can be reached from the tagged behaviours of randomly selected short segments of an online tutoring session. The sample size in our study was 44 tutors. For sure, it would be desirable to have a larger set of data, but organizational and human resources constraints make it difficult to obtain such a set. Nevertheless, the same problem is present in previously published related studies that focus on teacher behaviours. For example, the sample size of Prieto et al. (2018) was two teachers in 12 classroom sections, Camacho et al. (2020) was three teachers in 18 learning activities, Prieto et al. (2016) was four teachers in 4 sessions of 35-40 mins, and Riel et al. (2018) was forty-two teachers. We are acknowledging that the findings of this study come from limited sample size and are required to be further confirmed in future studies. However, in comparison to recent research in the field, our sample size is comparable.

Finally, the ground truth used in our classification is based on the rankings provided by human evaluators. These rankings are likely to include a level of human bias and inconsistency. We would recommend that future work use alternative versions of the ground truth including relatively more standardised measures such as learners' content acquisition. In addition, this study does not include any particular qualitative evaluation, such as tutor interviews. Although students' post-session feedback was taken into account in the tutor evaluations, detailed interviews with students could also generate insights into how satisfied they are with different tutoring practices. As such, we are unable to triangulate our findings with tutor self-reports. Triangulation would enable us to further validate our findings, and enable a richer discussion of the inferences that can be drawn from the tutor behaviours observed.

\section{Conclusion}

This article investigates the nature of effective tutor behaviours in online one-to-one tutoring settings and proposes a learning analytics approach to monitor the quality of online tutoring. Our results showed statistically significant differences in the sequences of effective vs less effective tutors' online tutoring behaviours. We illustrated that the sequential pattern behaviours of tutors can be used to accurately classify tutor effectiveness in online tutoring settings. The effectiveness of an online one-to-one tutoring session is complex and not a problem that can be addressed with one particular approach. However, the results we presented here provide promising opportunities for providing analytics solutions to monitor the quality of online one-to-one tutoring more efficiently, improving the current practice through the implications of its findings, and also generating various future research opportunities.

\section{Declaration of Conflicting Interest}

We declare no potential conflicts of interest with respect to the research, authorship, and/or publication of this article.

\section{Acknowledgements}

We would like to thank online tutors and the Third Space Learning tutoring company for granting permission to collect data for this study. The lead author would like to acknowledge that this research was partially funded by University College London's Strategic Partner fund and the Institute of Education's CMM Departmental seed funding. Eva Millán has been partially funded by the Spanish Government, Agencia Estatal de Investigación (AEI) and European Union, Fondo Europeo de DesarrolloRegional (FEDER), grant TIN2016-80774-R (AEI/FEDER, UE) and by the University of Málaga. 


\section{References}

Amiri, M., \& Ghonsooly, B. (2015). The relationship between english learning anxiety and the students' achievement on examinations. Journal of Language Teaching and Research, 6, 855-865.

Anania, J. (1983). The influence of instructional conditions on student learning and achievement. Evaluation in Education: An International Review Series, 7, 3-76.

Andres, J. M. A. L., Ocumpaugh, J., Baker, R. S., Slater, S., Paquette, L., Jiang, Y., Karumbaiah, S., Bosch, N., Munshi, A., Moore, A. et al. (2019). Affect sequences and learning in betty's brain. In Proceedings of the 9th International Conference on Learning Analytics \& Knowledge (pp.383-390).

Boroujeni, M. S., \& Dillenbourg, P. (2019). Discovery and temporal analysis of MOOC study patterns. Journal of Learning Analytics, 6, 16-33.

Butler, A. C., Karpicke, J. D., \& Roediger III, H. L. (2007). The effect of type and timing of feedback on learning from multiple-choice tests. Journal of Experimental Psychology: Applied, 13, 273.

Camacho, V. L., de la Guía, E., Olivares, T., Flores, M. J., \& Orozco-Barbosa, L. (2020). Data Capture and Multimodal Learning Analytics Focused on Engagement With a New Wearable IoT Approach. IEEE Transactions on Learning Technologies, 13(4), 704-717.

Carter Jr, R. A., Rice, M., Yang, S., \& Jackson, H. A. (2020). Self-regulated learning in online learning environments: strategies for remote learning. Information and Learning Sciences, Vol. 121 No. 5/6, pp. 321-329. https://doi.org/10.1108/ILS-04-2020-0114

Chi, M. T., Bassok, M., Lewis, M. W., Reimann, P., \& Glaser, R. (1989). Self-explanations: How students study and use examples in learning to solve problems. Cognitive science, 13, 145-182.

Chi, M. T., De Leeuw, N., Chiu, M.-H., \& LaVancher, C. (1994). Eliciting self-explanations improves understanding. Cognitive science, 18, 439-477.

Cukurova, M., Mavrikis, M., Luckin, R., Clark, J., \& Crawford, C. (2017). Interaction analysis in online maths human tutoring: The case of third space learning. In international conference on artificial intelligence in education (pp. 636643). Springer, Cham.

Cullinane, C., \& Montacute, R. (2020). Covid-19 and social mobility impact brief\# 1: school shutdown. Sutton Trust.

Donald, C., Blake, A., Girault, I., Datt, A., \& Ramsay, E. (2009). Approaches to learning design: past the head and the hands to the heart of the matter. Distance Education, 30, 179-199.

D’Mello, S., \& Graesser, A. (2012). Dynamics of affective states during complex learning. Learning and Instruction, 22, $145-157$.

Gitinabard, N., Heckman, S., Barnes, T., \& Lynch, C. F. (2019). What will you do next? a sequence analysis on the student transitions between online platforms in blended courses. arXiv preprint arXiv:1905.00928

Graesser, A. C. (1993). Questioning mechanisms during tutoring, conver- sation, and human-computer interaction. Technical Report MEMPHIS STATE UNIV TN DEPT OF PSYCHOLOGY.

Graesser, A. C., Person, N., Harter, D., Group, T. R. et al. (2000). Teaching tactics in autotutor. Modelling human teaching tactics and strategies, In- ternational Journal of Artificial Intelligence in Education, 11 , 1020-1029.

Graesser, A. C., Person, N. K., \& Magliano, J. P. (1995). Collaborative dialogue patterns in naturalistic one-to-one tutoring. Applied cognitive psychology, $9,495-522$.

Hacker, D. J., Dole, J. A., Ferguson, M., Adamson, S., Roundy, L., \& Scarpulla, L. (2015). The short-term and maintenance effects of self- regulated strategy development in writing for middle school students. Reading \& Writing Quarterly, 31, $351-372$.

Hastie, M., Chen, N.-S., \& Kuo, Y.-H. (2007). Instructional design for best practice in the synchronous cyber classroom. Journal of Educational Technology \& Society, 10, 281-294.

Hodges, C., Moore, S., Lockee, B., Trust, T., \& Bond, A. (2020). The difference between emergency remote teaching and online learning. Educause Review, 27.

Hwang, G.-J., Hsu, T.-C., Lai, C.-L., \& Hsueh, C.-J. (2017). Interaction of problem-based gaming and learning anxiety in language students' english listening performance and progressive behavioral patterns. Computers \& Education, 106 , $26-42$.

Jerrim, J. (2017). Extra time: Private tuition and out-of-school study, new international evidence. Sutton Trust.

Johnson, G. M., \& Bratt, S. E. (2009). Technology education students: e-Tutors for school children. British Journal of Educational Technology, 40(1), 32-41. 
Khan-Galaria, M., Cukurova, M., \& Luckin, R. (2020). A Framework for Exploring the Impact of Tutor Practices on Learner Self-regulation in Online Environments. In International Conference on Artificial Intelligence in Education (pp. 135139). Springer, Cham.

Kinnebrew, J. S., Loretz, K. M., \& Biswas, G. (2013). A contextualized, differential sequence mining method to derive students' learning behavior patterns. Journal of Educational Data Mining, 5, 190-219.

Kopp, B., Matteucci, M. C., \& Tomasetto, C. (2012). E-tutorial support for collaborative online learning: An explorative study on experienced and inexperienced e-tutors. Computers \& Education, 58, 12-20.

Kulik, J. A., \& Kulik, C.-L. C. (1988). Timing of feedback and verbal learn- ing. Review of educational research, 58, $79-97$.

Lefevre, D., \& Cox, B. (2017). Delayed instructional feedback may be more effective, but is this contrary to learners' preferences? British Journal of Educational Technology, 48, 1357-1367.

Lepper, M. R., \& Woolverton, M. (2002). The wisdom of practice: Lessons learned from the study of highly effective tutors. In Improving academic achievement (pp. 135-158). Elsevier.

Lin, X., Schwartz, D. L., \& Hatano, G. (2005). Toward teachers' adaptive metacognition. Educational psychologist, 40 , 245-255.

Maldonado, R. M., Yacef, K., Kay, J., Kharrufa, A., \& Al-Qaraghuli, A. (2011). Analysing frequent sequential patterns of collaborative learning activity around an interactive tabletop. In Proceedings of the Educational Data Mining Conrefence .

Malekian, D., Bailey, J., \& Kennedy, G. (2020). Prediction of students' assessment readiness in online learning environments: the sequence matters. In Proceedings of the Tenth International Conference on Learning Analytics \& Knowledge (pp. 382-391).

Matcha, W., Gasevic, D., Jovanovic, J., Pardo, A., Lim, L., Maldonado-Mahauad, J., Gentili, S., Perez-Sanagustı, M., Tsai, Y.-S. et al. (2020). Analytics of learning strategies: Role of course design and delivery modality. Journal of Learning Analytics, 7, 45-71.

Mathan, S. A., \& Koedinger, K. R. (2002). An empirical assessment of com- prehension fostering features in an intelligent tutoring system. In International Conference on Intelligent Tutoring Systems (pp. 330-343). Springer.

Merrill, D. C., Reiser, B. J., Ranney, M., \& Trafton, J. G. (1992). Effective tutoring techniques: A comparison of human tutors and intelligent tutoring systems. The Journal of the Learning Sciences, 2, 277-305.

Narciss, S., \& Huth, K. (2004). How to design informative tutoring feed- back for multimedia learning. Instructional design for multimedia learning, p.181-195.

Ozdagoglu, G., Oztas, G. Z., \& Cagliyangil, M. (2019). An application framework for mining online learning processes through event-logs. Business Process Management Journal, Vol. 25 No. 5, pp. 860-886. https://doi.org/10.1108/BPMJ-10-2017-0279.

Pardos, Z. A., Baker, R. S., San Pedro, M. O., Gowda, S. M., \& Gowda,

S. M. (2013). Affective states and state tests: Investigating how affect

throughout the school year predicts end of year learning outcomes. In Proceedings of the international conference on learning analytics and knowledge (pp. 117-124).

Pekrun, R., Goetz, T., Titz, W., \& Perry, R. P. (2002). Academic emotions in students' self-regulated learning and achievement: A program of qualitative and quantitative research. Educational psychologist, 37, 91-105.

Plass, J. L., Heidig, S., Hayward, E. O., Homer, B. D., \& Um, E. (2014). Emotional design in multimedia learning: Effects of shape and color on affect and learning. Learning and Instruction, 29, 128-140.

Prieto, L. P., Sharma, K., Dillenbourg, P., \& Jesús, M. (2016). Teaching analytics: towards automatic extraction of orchestration graphs using wearable sensors. In Proceedings of the sixth international conference on learning analytics \& knowledge (pp. 148-157).

Prieto, L. P., Sharma, K., Kidzinski, Ł., Rodríguez-Triana, M. J., \& Dillenbourg, P. (2018). Multimodal teaching analytics: Automated extraction of orchestration graphs from wearable sensor data. Journal of computer assisted learning, 34(2), 193-203.

Rapanta, C., Botturi, L., Goodyear, P., Gu'ardia, L., \& Koole, M. (2020). Online university teaching during and after the covid-19 crisis: Refocusing teacher presence and learning activity. Postdigital Science and Education, (pp. 1-23).

Riel, J., Lawless, K. A., \& Brown, S. W. (2018). Timing Matters: Approaches for Measuring and Visualizing Behaviours of Timing and Spacing of Work in Self-Paced Online Teacher Professional Development Courses. Journal of Learning Analytics, 5(1), 25-40. https://doi.org/10.18608/jla.2018.51.3

Ritter, S., Anderson, J. R., Koedinger, K. R., \& Corbett, A. (2007). Cognitive tutor: Applied research in mathematics education. Psychonomic bulletin \& review, 14, 249-255.

15

ISSN 1929-7750 (online). The Journal of Learning Analytics works under a Creative Commons License, Attribution - NonCommercial-NoDerivs 3.0 Unported (CC BY-NC-ND 3.0) 
Ryan, R. M., \& Deci, E. L. (2009). Promoting self-determined school engagement: Motivation, learning, and well-being. In K. R. Wenzel \& A. Wigfield (Eds.), Educational psychology handbook series. Handbook of motivation at school (p. 171-195). Routledge/Taylor \& Francis Group.

Saint, J., Gasevic, D., Matcha, W., Uzir, N. A., \& Pardo, A. (2020). Combining analytic methods to unlock sequential and temporal patterns of self-regulated learning. In Proceedings of the Tenth International Conference on Learning Analytics \& Knowledge (pp. 402-411).

Schmidt, H. G., Dolmans, D., Gijselaers, W. H., \& Des Marchais, J. E. (1995). Theory-guided design of a rating scale for course evaluation in problem-based curricula. Teaching and Learning in Medicine: an international journal , 7, 8291.

Shield, M., \& Dole, S. (2013). Assessing the potential of mathematics text- books to promote deep learning. Educational Studies in Mathematics, 82, 183-199.

Shorrocks-Taylor, D., \& Hargreaves, M. (1999). Making it clear: A review of language issues in testing with special reference to the national curriculum mathematics tests at key stage 2. Educational Research, 41, 123-136.

Shute, V. J. (2008). Focus on formative feedback. Review of educational research, 78, 153-189.

Sleeman, D., Kelly, A. E., Martinak, R., Ward, R. D., \& Moore, J. L. (1989). Studies of diagnosis and remediation with high school algebra students. Cognitive Science, 13, 551-568.

Torgerson, C., Ainsworth, H., Buckley, H., Hampden-Thompson, G., Hewitt, C., Humphry, D., Jefferson, L., Mitchell, N., \& Torgerson, D. (2016). Affordable online Maths tuition: evaluation report and executive summary. Education Endowment Foundation.

Walsh, J. A., \& Sattes, B. D. (2016). Quality questioning: Research-based practice to engage every learner . Corwin Press.

Wang, Y., Li, T., Geng, C., \& Wang, Y. (2019). Evaluating student learning effect based on process mining. In International Conference on Applied Informatics (pp. 59-72). Springer.

Wittwer, J., Nückles, M., Landmann, N., \& Renkl, A. (2010). Can tutors be supported in giving effective explanations? Journal of Educational Psychology, $102,74$.

Wittwer, J., Nu"ckles, M., \& Renkl, A. (2008). Is underestimation less detrimental than overestimation? the impact of experts' beliefs about a layperson's knowledge on learning and question asking. Instructional Science, 36, $27-52$.

Wong, J., Khalil, M., Baars, M., de Koning, B. B., \& Paas, F. (2019). Exploring sequences of learner activities in relation to self-regulated learning in a massive open online course. Computers \& Education, $140,103595$.

Wylie, R., \& Chi, M. T. (2014). 17 the self-explanation principle in multimedia learning. The Cambridge handbook of multimedia learning, (p. 413).

Zheng, J., Xing, W., \& Zhu, G. (2019). Examining sequential patterns of self-and socially shared regulation of stem learning in a cscl environment. Computers \& Education, 136, 34-48. 